\title{
Analysis of Laterally Loaded Piles in Undrained Clay Concave Slope
}

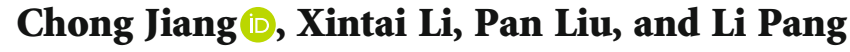 \\ School of Resources and Safety Engineering, Central South University, Changsha, 410083 Hunan, China \\ Correspondence should be addressed to Chong Jiang; jiang4107@sohu.com
}

Received 14 May 2021; Accepted 1 July 2021; Published 23 July 2021

Academic Editor: Yu Wang

Copyright (C) 2021 Chong Jiang et al. This is an open access article distributed under the Creative Commons Attribution License, which permits unrestricted use, distribution, and reproduction in any medium, provided the original work is properly cited.

\begin{abstract}
A concave slope is a common type of slope. This paper proposes a simplified method to study the effect of a clay concave slope on laterally loaded piles. The hyperbolic $p-y$ curve model is selected as the lateral pile-soil interaction model of the concave slope. Considering the two angles of the concave slope, the variation of the ultimate soil resistance with depth is divided into two parts, and the ultimate soil resistance varies nonlinearly with depth. The reduction factor method and normalization method are used to obtain the initial stiffness. The theoretical results will be compared with the calculation results of the 3D FE analysis to prove the rationality of this method. Finally, the simplified method is used to analyze the response of laterally loaded piles under different parameters.
\end{abstract}

\section{Introduction}

Pile foundation is one of the most commonly used foundations in bridge engineering, offshore drillings, and offshore wind turbines. These pile foundations are often used on sloping ground, such as river valleys and the seabed $[1,2]$. The pile foundation will be subjected to lateral loads caused by traffic loads, lateral wind, and waves.

The bearing capacity of pile foundations depends on the bearing capacity of the rock and soil around the pile. There are three main approaches to study the bearing capacity of rock and soil around the pile: theoretical methods $[3,4]$, numerical simulations [5], and experimental methods [6]. In the past few decades, the $p-y$ curve method is often used to study the response of pile foundation bearing lateral load. The main research includes the influence of laterally loaded piles in flat ground and sloping ground. For the flat grounds, many scholars and institutions proposed $p-y$ curves for different types of soil [7-9]. For the sloping ground, the soil in front of the pile is weakened, and the damage model of soil is different from that in the horizontal ground [10-12]. Therefore, Reese et al. [13] proposed $p-y$ curves that were suitable for sand and clay sloping ground, respectively. Based on the 3D FE analysis, Georgiadis and Georgiadis [14, 15] obtained the $p-y$ curves suitable for clay sloping ground. On this basis, the $p-y$ curves of clay sloping ground were proposed, which considered the distance between the slope and pile. But all the $p-y$ methods mentioned above only considered level ground and single-angle slope.

However, due to the influence of external factors such as rain erosion and soil accumulation, the slope has more than two angles. Wu et al. [16] and Fan et al. [17] pointed out that slope shapes could be roughly divided into four types, which were the straight type with a single angle, the convex type (the upper slope angle is smaller than the lower slope angle), the concave type (the upper slope angle is greater than the lower slope angle), and a mixed type.

The $p-y$ method is widely used in engineering because of its simple calculation and short calculation time. However, compared to a slope with a single angle, the distribution law of the concave slope's ultimate soil resistance and initial stiffness will change. But unfortunately, the existing $p-y$ curves of sloping ground can only consider the change law of ultimate soil resistance and initial stiffness under a single angle. It leads to errors in the analysis of the horizontal bearing characteristics of piles using the existing $p-y$ curve. 


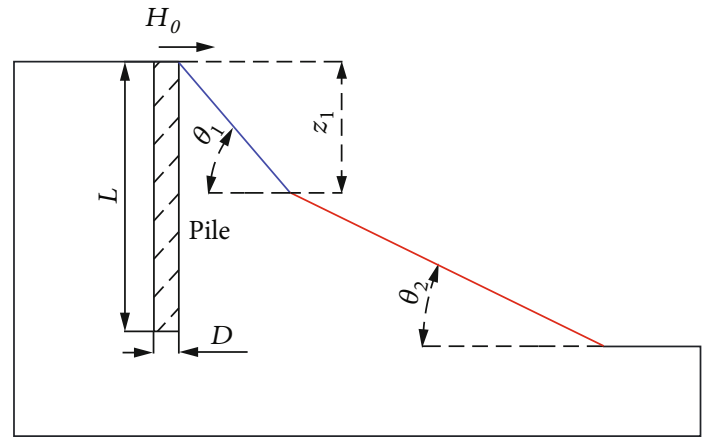

Figure 1: Analysis model of a laterally loaded pile on a concave slope. Here, $L$ is the length of the pile embedded in the soil, $D$ is the pile diameter, $H_{0}$ is the lateral load on the pile head, $\theta_{1}$ is the upper slope angle, $\theta_{2}$ is the lower slope angle, and $Z_{1}$ is the upper slope height.

Therefore, it is necessary to carry out further research on the lateral load characteristics and calculation methods of concave slope piles.

This paper focuses on giving a nonlinear analysis method considering the bearing characteristics of the laterally loaded pile in concave sloping ground. In this method, the pile-soil interaction model adopts the hyperbolic $p$ - $y$ curve model. And the calculation formula of the ultimate soil resistance and the initial stiffness varying with depth in the concave slope is given. Then, the derived $p-y$ curve is brought into MATLAB for a differential calculation to obtain the nonlinear response of the pile under a lateral load. To prove the correctness, the method is verified by the results of threedimensional finite element analysis considering the concave clay slope. Furthermore, this article discusses the influence of the different slope angles and upper slope height and obtains the response law of piles under the influence of different parameters.

\section{Establish a $p-y$ Curve of Clay Concave Slope}

At present, the $p$ - $y$ curve method, which regards soil as a nonlinear spring, is widely used to study the lateral load response of the horizontal ground piles. There are many kinds of mathematical models of the $p-y$ curve. One of the most widely used is the hyperbolic $p-y$ curve [18-21]. The expression is shown as follows:

$$
p=\frac{y}{\left(1 / k_{i}\right)+\left(y / p_{u}\right)}
$$

where $p_{u}=$ ultimate soil resistance of the soil along the pile, $K_{i}=$ initial stiffness of the foundation.

Yang [22] compared different types of $p-y$ curves and concluded that the hyperbolic $p-y$ curve has the best fitting effect with the data obtained from field experiments. Therefore, this article adopts a hyperbolic $p-y$ curve.

2.1. Basic Assumption. To analyze the influence of the concave slope which has two angles on the horizontal bearing characteristics of the pile, an analysis model is established, as shown in Figure 1.

For simplicity, the following assumptions are made:

(1) The slope is stable without a sliding surface, and slope failure and instability are not considered in the calculation

(2) The soil resistance along the pile changes nonlinearly with the increase in lateral displacement. When the ultimate soil resistance is achieved, its value remains constant as the increase in lateral displacement

(3) This article only considers concave slopes, the upper slope angle is larger than the lower slope angle, $\theta_{1}>\theta_{2}$

2.2. Ultimate Soil Resistance of Concave Slope Varying with Depth. For the ultimate soil resistance $p_{u}$, its expression is as follows:

$$
p_{u}=N_{p} c_{u} D
$$

where $N_{p}$ is the ultimate soil-resistance-bearing factor, $c_{u}$ is the undrained shear strength of soil, $D$ is the pile diameter.

Equation (3) shows that the value of $N_{p}$ changes nonlinearly with the increase in depth [14]. The initial value of $N_{p}$ is $N_{p o} \cos (\theta)$ at the ground surface, and the maximum value is $N_{p u}$ :

$$
N_{p}=N_{p u}-\left(N_{p u}-N_{p o} \cos (\theta)\right) e^{((-\lambda(z / D)) /(1+\tan (\theta)))} .
$$

The value of $N_{p o}, N_{p u}$, and $\lambda$ are related to the adhesion factor $\alpha$ of the pile-soil interface $[23,24])$.

The adhesion factor $\alpha$ is the ratio of the interface shear strength to the undrained shear strength of the soil. In this article, $\alpha$ can be obtained from Figure 2 [14].

When $0 \leq c_{u}<25$, we have

$$
\alpha=1
$$

When $25 \leq c_{u}<80$, we have

$$
\alpha=\frac{14}{11}-\frac{3}{275} c_{u}
$$

When $80 \leq c_{u}<200$, we have

$$
\alpha=0.5-\frac{1}{800} c_{u}
$$

$\lambda$ is a dimensionless parameter that changes with the adhesion factor. For smooth piles, $\lambda$ is $0.55(\alpha=0)$; for rough piles, $\lambda$ is $0.4(\alpha=1)$ :

$$
\lambda=0.55-0.15 \alpha \text {. }
$$




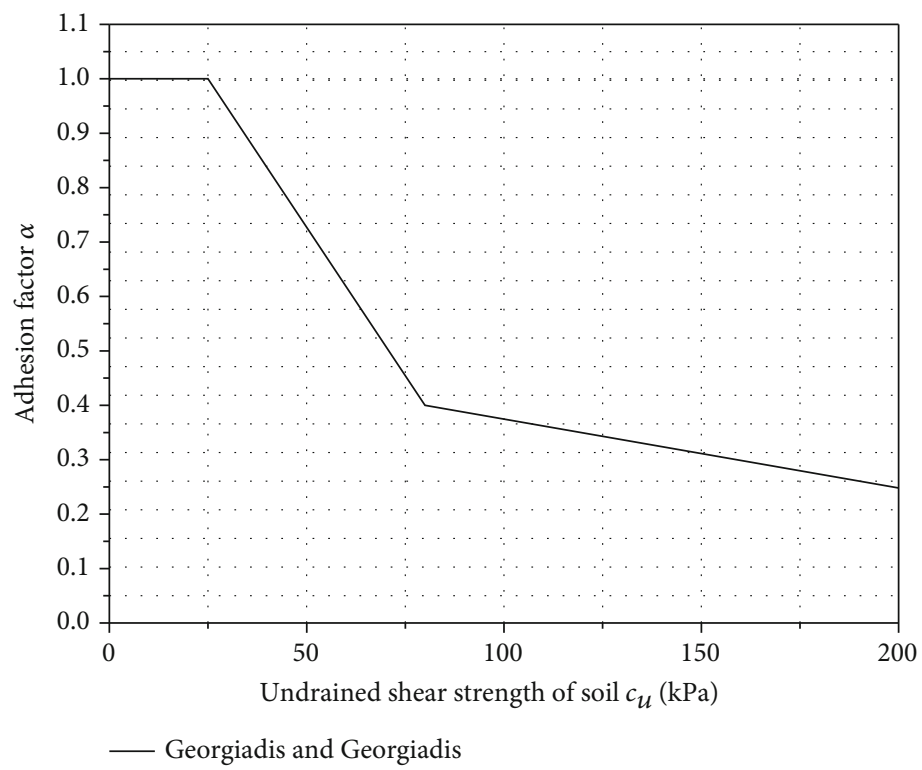

FIGURE 2: The relationship between $\alpha$ and $c_{u}$.

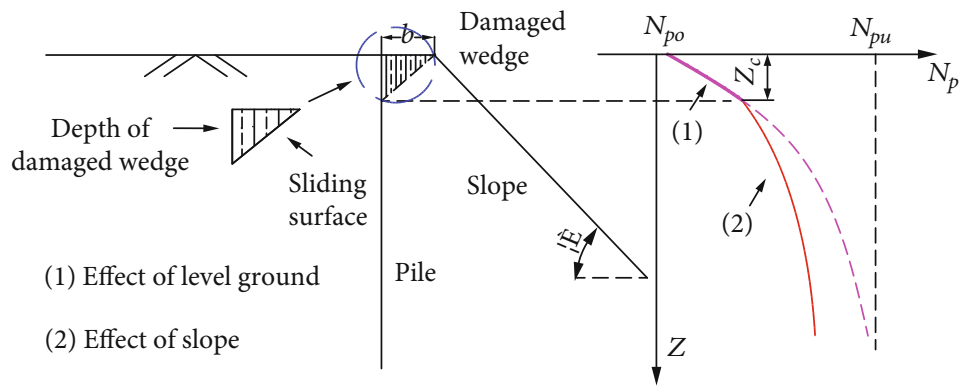

(a)

(b)

FIGURE 3: Ultimate soil resistance analytical model with the distance of piles from the crest of the slope. (a) Damaged wedge model of the laterally loaded piles. (b) The $N_{p}$ curve varying with the depth.

$N_{p o}$ is the ultimate soil-resistance-bearing factor at the ground surface:

$$
N_{p o}=2+1.5 \alpha
$$

$N_{p u}$ is the ultimate soil-resistance-bearing factor based on the deep soil flow failure model by Randolph and Houlsby [25]:

$$
N_{p u}=\pi+2 \Delta+2 \cos \Delta+4\left(\cos \frac{\Delta}{2}+\sin \frac{\Delta}{2}\right),
$$

where $\Delta=\sin ^{-1} \alpha$.

To obtain the ultimate soil resistance along the pile in concave sloping ground, the ultimate soil-resistance-bearing factor $N_{p}$ is the key.

Jiang et al. [26] found that with the increase in the lateral displacement of the pile in sloping ground, the stress and strain of the soil show a wedge-shaped distribution in the three-dimensional numerical simulation. Similarly, Georgiadis and Georgiadis [15] found the same rule when studying the influence of the distance between the pile and slope on laterally loaded piles, as shown in Figure 3.

It shows in Figure 3(a) that when the pile head deflection is small, the soil has a damaged wedge in a shallow soil. The sliding surface of the damaged wedge only intersects with the level ground. Therefore, the slope will not affect the ultimate soil resistance near the mudline. As the pile head deflection augments, the depth of the damaged wedge increases. When the depth of the damaged wedge reaches $Z_{c}$, the sliding surface of the wedge spreads to the slope. As shown in Figure 3(b), when the depth of the damaged wedge is less than $Z_{c}$, the expression of the ultimate soil-resistancebearing factor $N_{p}$ is the same as that of the flat ground since the pile is only affected by the level ground. When the sliding surface of the damaged wedge intersects with the slope surface, the ultimate soil resistance along the pile is weakened compared to the level ground. The expression of $N_{p}$ needs to consider the influence of the slope. 


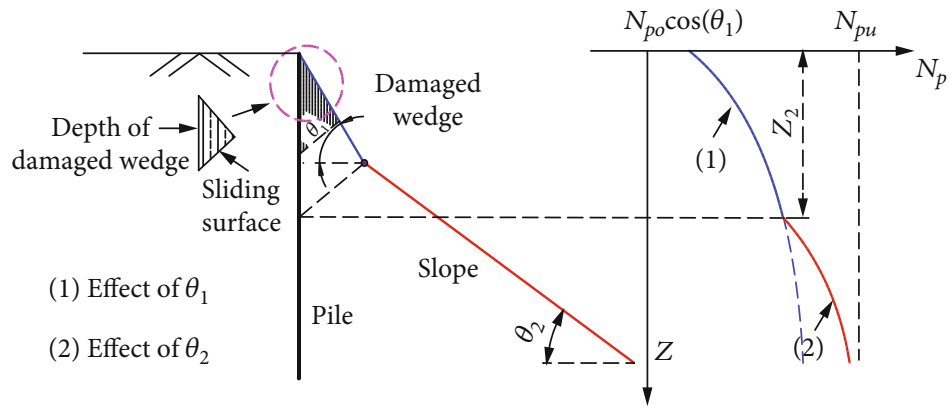

(a)

(b)

FIGURE 4: Ultimate soil resistance analytical model of the concave sloping ground. (a) Damaged wedge model of laterally loaded piles on the concave slope. (b) The $N_{p}$ curve along the pile on concave slope.

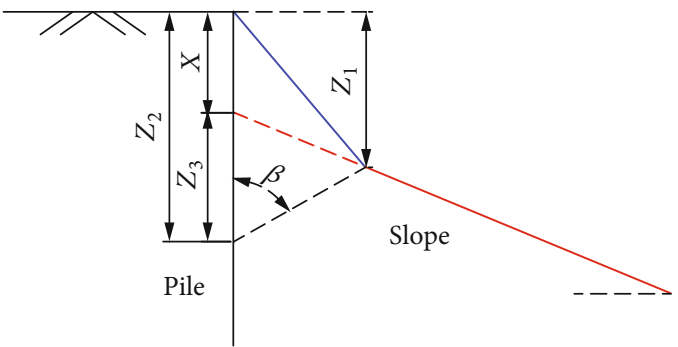

Figure 5: The definition of height difference $X$.

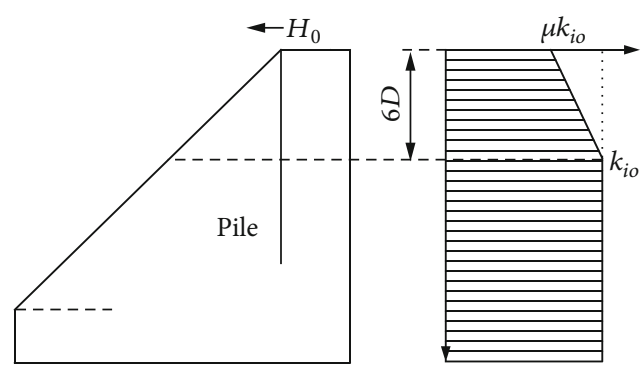

FIgURE 6: Initial stiffness model of slope foundation.
Georgiadis and Georgiadis [15] believed that the depth of the damaged wedge would change with the increase of lateral load, and it had a nonlinear relationship with the distance of pile from the crest of the slope. When the sliding surface intersects with the slope crest, the critical depth $Z_{c}$ is expressed as follows:

$$
\frac{Z_{c}}{D}=8.5-10 \log _{10} \frac{(8-\mathrm{b})}{D}
$$

where $b$ indicates the distance from the pile core to the crest of the slope. When $b=0.5 D$, the pile is at the crest of the slope.

For concave slopes, this article will use the same method to get the expression of $N_{p}$, as shown in Figure 4 .

Figure 4(a) shows that the sliding surface of the damaged wedge intersects the slope with the angle of $\theta_{1}$ when $0 \leq Z<Z_{2}$, and the ultimate soil resistance is only affected by the upper slope. When the depth reaches $Z_{2}$, the sliding surface of the wedge intersects with the intersection of the upper slope and lower slope. When the depth is greater than $Z_{2}$, the sliding surface intersects the slope with the angle of $\theta_{2}$, and the lower slope begins to affect the ultimate soil resistance. It is pointed out in Figure 4(b) the changing law of $N_{p}$ in the concave slope with two angles. The expression of $N_{p}$ is only controlled by $\theta_{1}$ when the depth of the damaged wedge is less than $Z_{2}$. When the depth is greater than $Z_{2}$, the expression of $N_{p}$ is affected by $\theta_{2}$. It is reasonable that the value of $N_{p}$ increases at $Z_{2}$ relative to that of the single-angle slope $\left(\theta_{1}\right)$ because the lower slope increases the volume of soil in front of the pile. To determine the critical depth $Z_{2}$, this paper adopts the modified critical depth expression:

$$
Z_{2}=\left[8.5-10 \log _{10}\left(8-\frac{\left(Z_{1} / \tan \left(\theta_{1}\right)\right)+0.5 D}{D}\right)\right] D+Z_{1} .
$$

Because the slope is a homogeneous medium, the expression of the ultimate soil resistance is continuous and derivable when the depth increases, and there will be no sudden change point. Therefore, when the depth reaches the critical depth $\left(Z_{2}\right)$, the piecewise function of $N_{p}$ should be the same value $N_{p}\left(Z_{2}\right)$, as shown in Figure $4(\mathrm{~b})$. When the value of $N_{p}$ is $N_{p}\left(Z_{2}\right)$, the corresponding depths are $Z_{2}$ for the slope with angle $\theta_{1}$ and $Z_{3}$ for the slope with angle $\theta_{2}$. And the difference between $Z_{2}$ and $Z_{3}$ is defined as $X$, as shown in Figure 5.

When the depth is less than $Z_{2}$, the expression of $N_{p 1}$ is as follows:

$$
N_{p 1}=N_{p u}-\left(N_{p u}-N_{p o} \cos \left(\theta_{1}\right)\right) e^{\left((-\lambda(z / D)) /\left(1+\tan \left(\theta_{1}\right)\right)\right)} .
$$

When the depth is greater than $Z_{2}$, the expression of $N_{p 2}$ is as follows: 


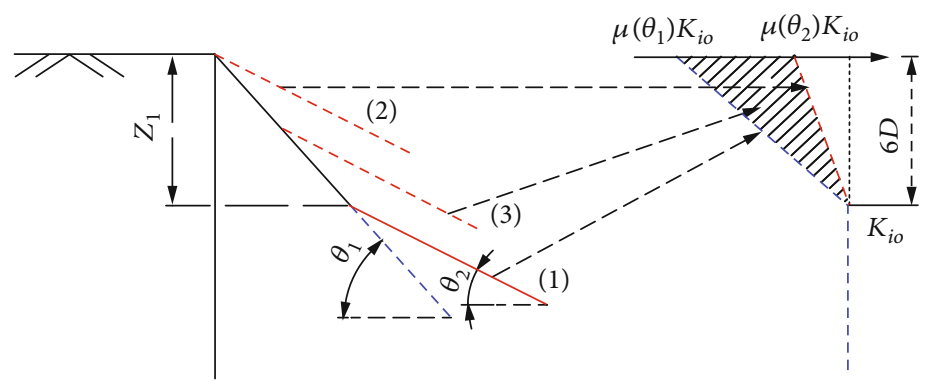

FIgURE 7: Initial stiffness model of concave sloping ground. (a) The concave sloping ground under 3 cases. (b) The value of initial stiffness under 3 cases.

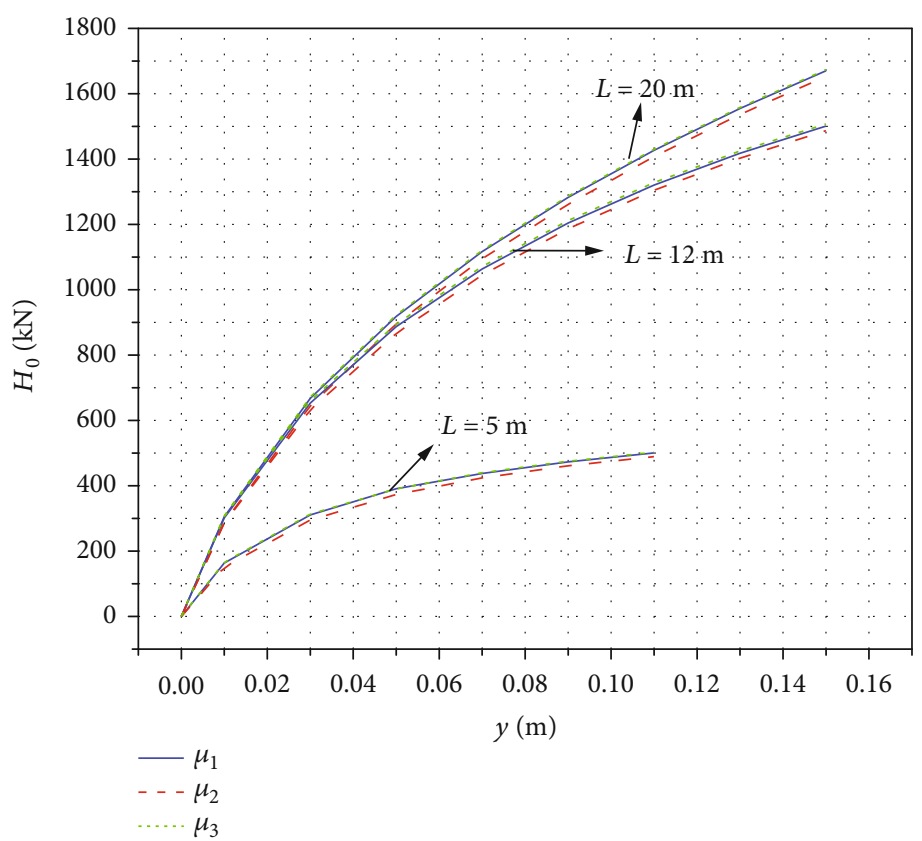

FIGURE 8: Effect of initial stiffness reduction factor on pile head deflection.

$$
\begin{gathered}
N_{p 2}=N_{p u}-\left(N_{p u}-N_{p o} \cos \left(\theta_{2}\right)\right) e^{\left(((-\lambda(Z-x)) / D) /\left(1+\tan \left(\theta_{2}\right)\right)\right)}, \\
N_{p}\left(Z_{2}\right)=N_{p u}-\left(N_{p u}-N_{p o} \cos \left(\theta_{1}\right)\right) e^{\left(\left(\left(-\lambda Z_{2}\right) / D\right) /\left(1+\tan \left(\theta_{1}\right)\right)\right)}, \\
Z_{3}=\ln \left[\frac{N_{p u}-N_{p}\left(Z_{2}\right)}{N_{p u}-N_{p o} \cos \left(\theta_{2}\right)}\right] \frac{D\left(1+\tan \left(\theta_{2}\right)\right)}{-\lambda}, \\
X=Z_{2}-Z_{3} .
\end{gathered}
$$

2.3. Initial Stiffness of Concave Slope Varying with Depth. Carter [27] proposed the expression of the initial stiffness $K_{i o}$ of the clay level ground, and believed that the initial stiffness is related to the initial elastic modulus of the soil, Poisson's ratio, and other factors:

$$
K_{i o}=\frac{1.0 E_{i} D}{\left(1-v_{s}^{2}\right) D_{\text {ref }}}\left(\frac{E_{i} D^{4}}{E_{p} I_{p}}\right)^{1 / 12},
$$

where $D$ is the pile diameter; $D_{\text {ref }}$ is the pile diameter reduction factor, usually taken as $1 ; E_{p} I_{p}$ is the bending stiffness of the pile; $v_{s}$ is the Poisson's ratio of the soil; $E_{i}$ is the initial elastic modulus of the soil.

Kondner and Robertson et al. [28, 29] proposed the equation of elasticity modulus $E_{50}$ and believed that the initial elastic modulus $E_{i}$ can be related to the elastic modulus at fifty percent of the failure stress $E_{50}$ :

$$
E_{50}=E_{i}\left(1-\frac{R_{f} \sigma}{\sigma_{f}}\right)
$$

where $\sigma$ is deviatoric stress; $E_{50}$ is elasticity modulus; $\sigma_{f}$ is deviatoric failure stress; $R_{f}$ is the ratio of deviatoric failure stress over deviatoric ultimate stress, usually taken equal to 0.8 .

Setting $R_{f}=0.8, \sigma / \sigma_{f}=0.5$, and $\nu_{s}=0.5$, equation (14) becomes 


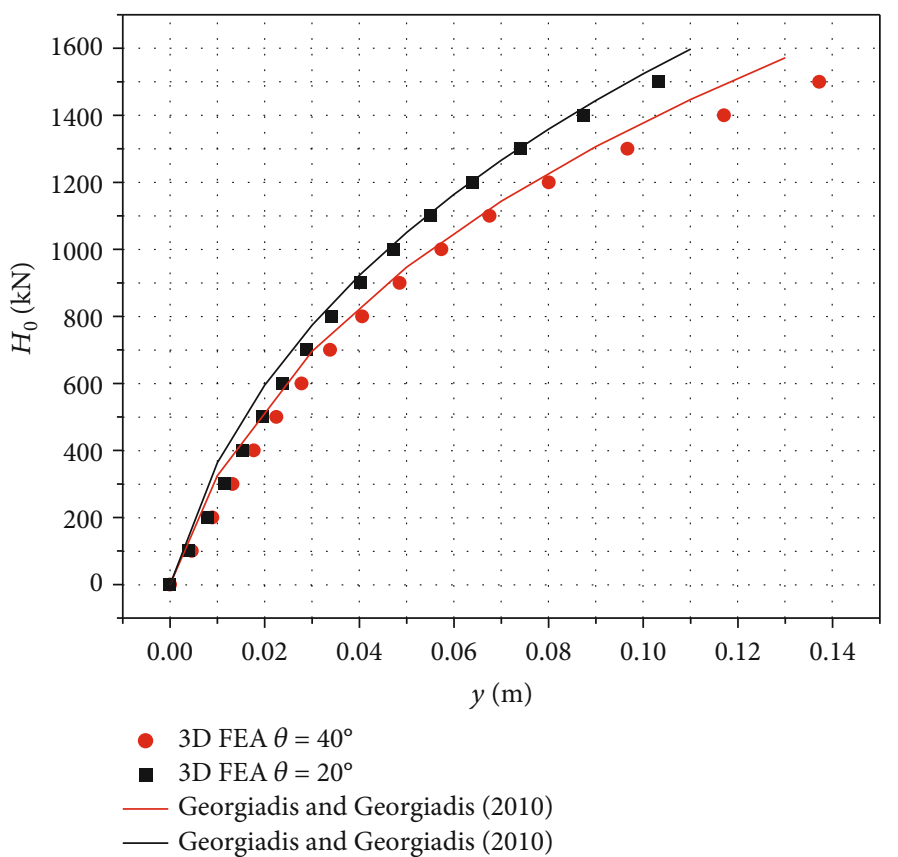

Figure 9: Deflection curve of pile head for comparison.

TABLE 1: Summary of three-dimensional numerical analysis conditions.

\begin{tabular}{lccccc}
\hline & $L(\mathrm{~m})$ & $D(\mathrm{~m})$ & $\theta_{1}$ & $\theta_{2}$ & $Z_{1}(\mathrm{~m})$ \\
\hline Case 1 & 20 & 1 & $40^{\circ}$ & $0^{\circ}$ & 1,3 \\
Case 2 & 20 & 1 & $50^{\circ}, 40^{\circ}$ & $30^{\circ}$ & 2 \\
& & & $40^{\circ}$ & $30^{\circ}$ & 1 \\
Case 3 & 12 & 1 & $45^{\circ}$ & $30^{\circ}$ & 2 \\
\hline
\end{tabular}

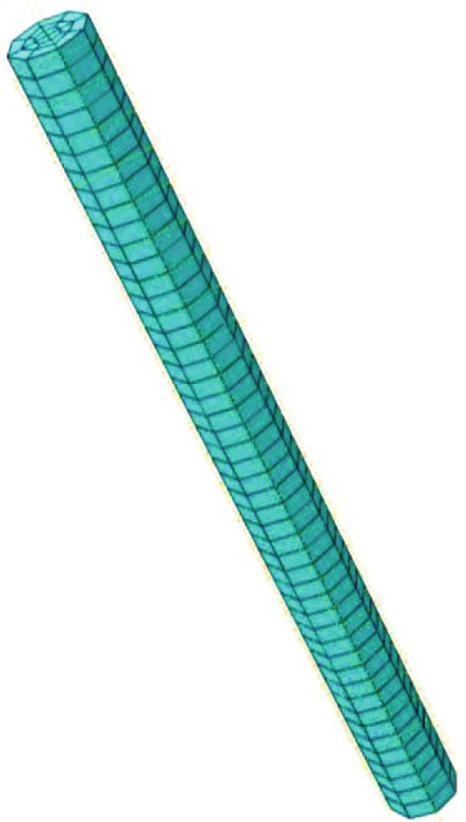

FIGURE 10: Three-dimensional model of the pile.

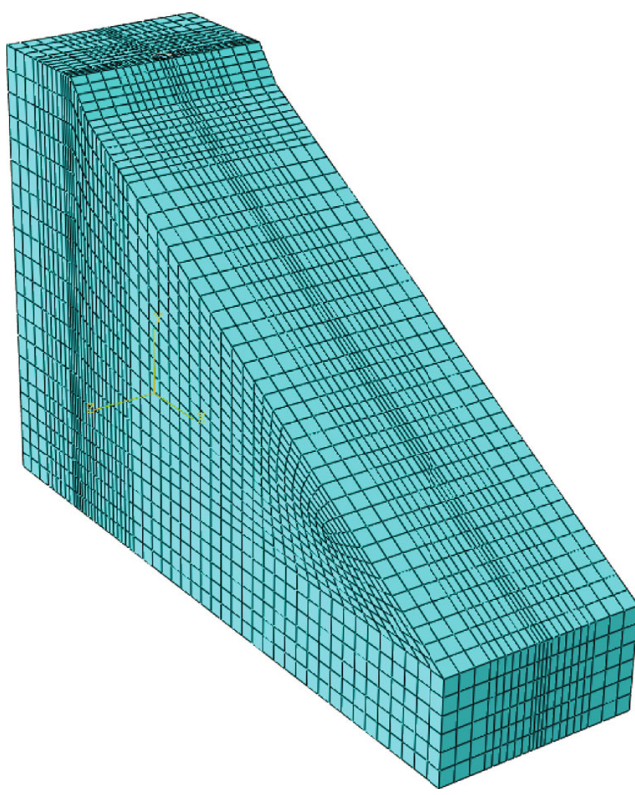

FIGURE 11: Three-dimensional model of concave slope.

$$
K_{i o}=2.3 D E_{50}\left(\frac{E_{50} D^{4}}{E_{p} I_{P}}\right)^{1 / 12}
$$

Equation (16) reveals that the initial stiffness of the foundation is only related to the characteristics of the soil and the pile. The normalization method is commonly used to obtain the initial stiffness expression of the sloping ground. On the basis of the initial stiffness expression of the level ground, many scholars adopt the reduction factor $\mu$ to establish the initial stiffness expression of the sloping ground $[14,30]$ : 


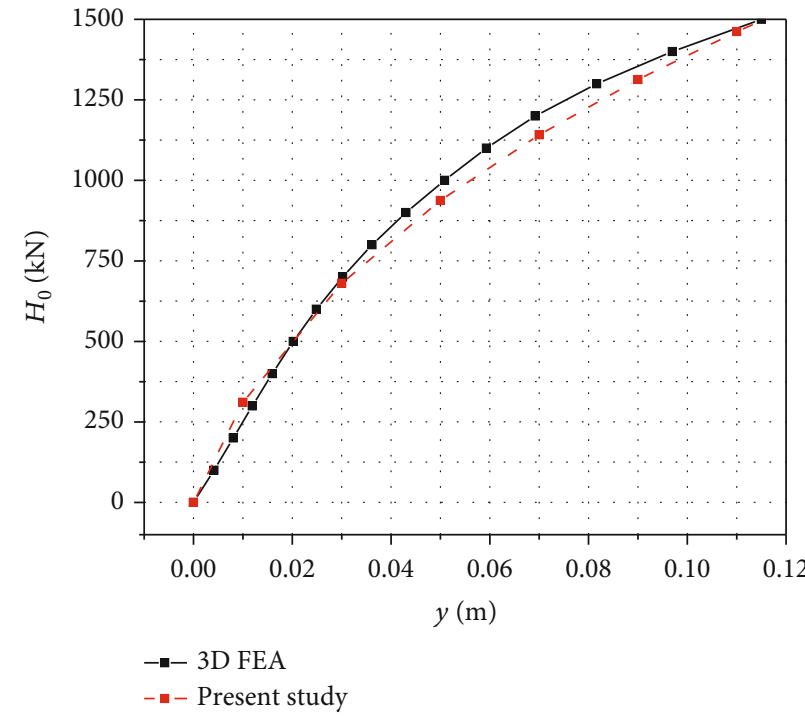

(a)

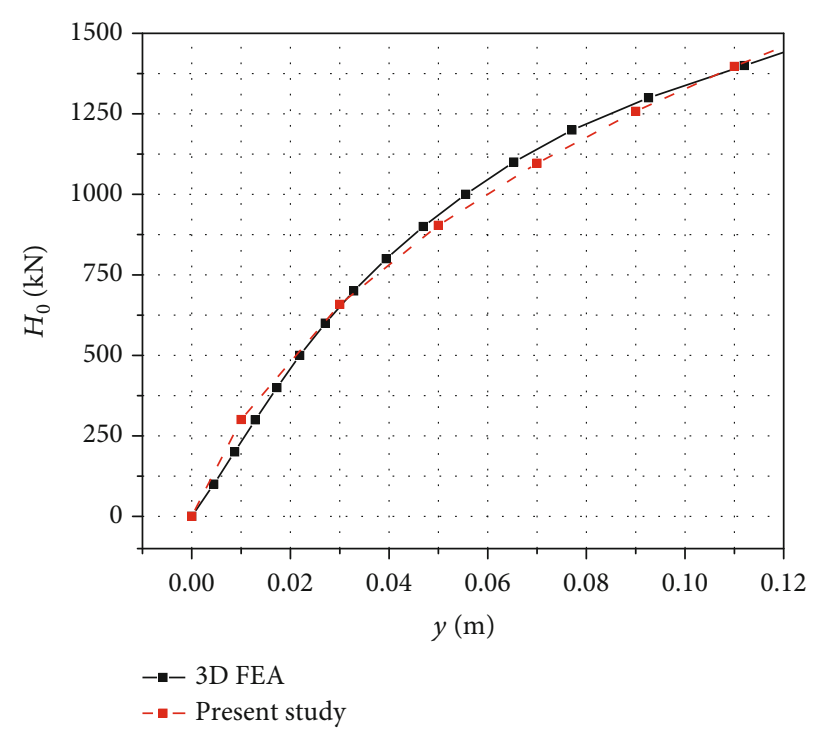

(b)

Figure 12: Load and displacement curve of pile head predicted for Case 2. (a) Considering $Z_{1}=1 \mathrm{~m}$. (b) Considering $Z_{1}=3 \mathrm{~m}$.

$$
\mu=\frac{K_{i}}{K_{i o}} \leq 1
$$

where $K_{i}$ is the initial stiffness of the sloping ground; $K_{i o}$ is the initial stiffness of the level ground.

When studying the influence of the initial stiffness of the sloping ground, Georgiadis and Georgiadis [14] proposed that the initial stiffness reduction factor is related to the depth of the slope, as shown in equation (18). The reduction factor $\mu$ changes linearly with the increase of depth, as shown in Figure 6. For slopes at an arbitrary angle, when the depth $Z$ is less than $6 D$, the slope weakens the initial stiffness, and the degree of weakening decreases when the depth becomes greater. When the depth is greater than $6 D$, the initial stiffness of the sloping ground is the same as that in level ground, and remains constant with the increase of depth:

$$
\mu=\cos (\theta)+\frac{Z}{6 D}(1-\cos (\theta))
$$

As shown in Figure 7, for a concave slope, when the value of $Z_{1}$ exceeds $6 D$ (red line (1) in Figure $7(\mathrm{a})$ ), the initial stiffness of the concave sloping ground at $Z_{1}$ reaches the value of that in level ground. The lower slope does not affect the initial stiffness, and the reduction factor $\mu$ is only controlled by the upper slope (blue line in Figure $7(\mathrm{~b})$ ). When $Z_{1}$ is 0 , the concave slope becomes a single-angle slope with $\theta_{2}$ (red line (2) in Figure $7(\mathrm{a}))$. The reduction factor $\mu$ is controlled by the slope with angle $\theta_{2}$ (red line in Figure $7(\mathrm{~b})$ ). When $Z_{1}$ ranges from 0 to $6 D$ (red line (3) in Figure $7(\mathrm{a})$ ), the reduction factor $\mu$ varies with depth in the range between the two limit conditions (shaded part in Figure 7(b)). Georgiadis and Georgiadis [14] point out that the reduction factor has a small effect on both pile head deflection and maximum bending moment. This paper assumes that the initial value of the reduction factor changes uniformly from $\mu\left(\theta_{2}\right)$ to $\mu\left(\theta_{1}\right)$ as $Z_{1}$ increases from 0 to $6 D$.

When $0<Z_{1}<6 D$, we have

$$
\begin{aligned}
& \mu_{1}=u_{1}+\frac{Z}{6 D}\left(1-u_{1}\right), \\
& u_{1}=\cos \left(\theta_{1}\right)+\left(\cos \left(\theta_{2}\right)-\cos \left(\theta_{1}\right)\right) \frac{6 D-Z_{1}}{6 D} .
\end{aligned}
$$

When $Z_{1} \geq 6 D$, we have

$$
\mu_{1}=\cos \left(\theta_{1}\right)+\frac{Z}{6 D}\left(1-\cos \left(\theta_{1}\right)\right) .
$$

And the initial stiffness of concave sloping foundation $K_{i \theta}$ can be expressed as follows:

$$
K_{i \theta}=\mu_{1} K_{i o}
$$

To verify the rationality of the above assumptions, three cases of reduction factors $\mu$ are used to obtain the pile head load-displacement curve. $\mu_{1}$ is calculated by the method in this paper, $\mu_{2}$ is obtained by the calculation method considering the single-angle slope with angle $\theta_{1}$, and $\mu_{3}$ is obtained from the calculation method considering the single-angle slope with angle $\theta_{2}$. Undrained shear strength $c_{u}=70 \mathrm{kPa}$, and elastic modulus of soil $E_{50}$ is $14 \mathrm{MPa}$. Pile diameter $D=1 \mathrm{~m}$; pile length $L=5 \mathrm{~m}, 12 \mathrm{~m}$, and $20 \mathrm{~m}$; and elastic modulus of piles $E_{p}=2.9 \times 10^{7} \mathrm{kPa} . \theta_{1}=40^{\circ} ; \theta_{2}=20^{\circ}$; and upper slope height $Z_{1}=1 \mathrm{~m}$. The load-displacement curve of the pile head under different conditions is shown in Figure 8. It indicates that the load-displacement curve of the pile head is almost unchanged even if $\mu$ is taken as two limit conditions $\left(\mu_{2}, \mu_{3}\right)$. For the pile length $L=5 \mathrm{~m}$, the maximum discrepancies are only $16 \%$. The above simplifying method is sufficient for determining the reduction factor. 


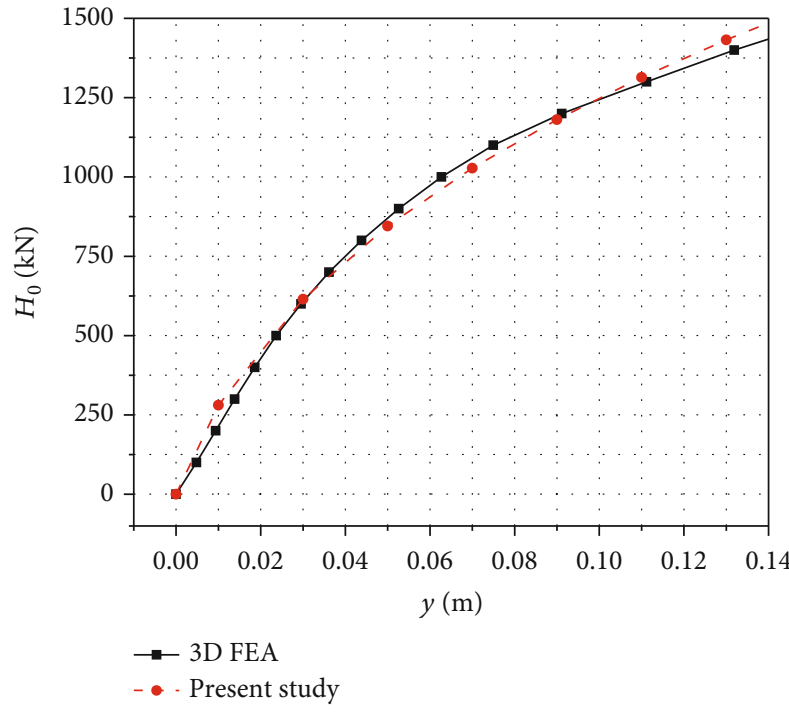

(a)

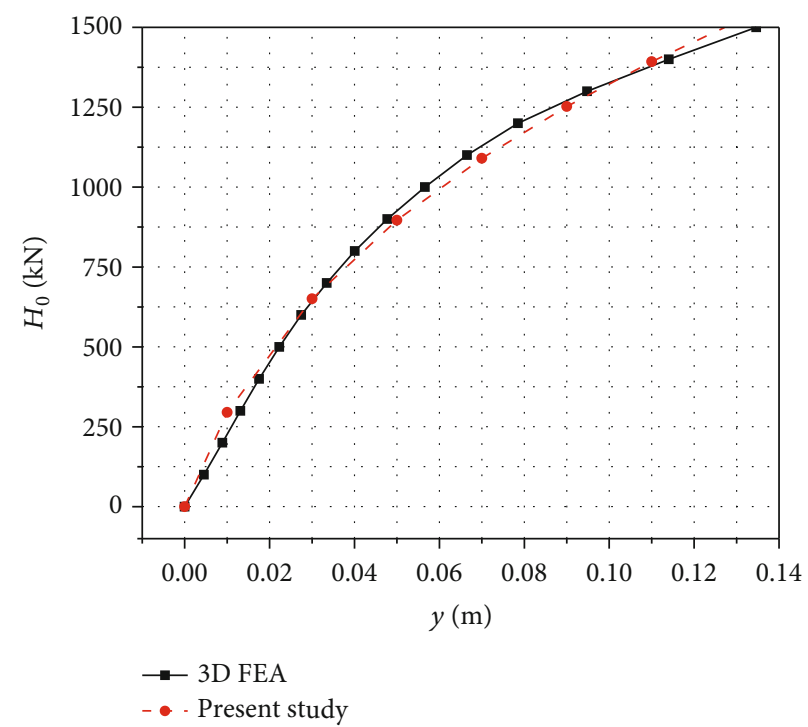

(b)

Figure 13: Load and displacement curve of pile head predicted for Case 2. (a) Considering $\theta_{1}=50^{\circ}$. (b) Considering $\theta_{1}=40^{\circ}$.

\section{Approach Verification}

A series of three-dimensional finite element analysis models of the laterally loaded pile in a concave slope is established to verify the correctness of the calculation method in this paper.

3.1. Establishment and Verification of 3D FEA Model. All the basic parameters of the 3D finite element analysis model in this paper are obtained from the literature $[5,14]$. The basic parameters of the pile are set as follows: pile length $L=20 \mathrm{~m}$; diameter $D=1 \mathrm{~m}$; elastic modulus of pile $E_{p}=2.9$ $\times 10^{7} \mathrm{kPa}$; Poisson's ratio of pile $v_{p}$ is 0.1 ; and the density of pile $\rho_{l}$ is $2500 \mathrm{~kg} / \mathrm{m}^{3}$. Piles are all embedded in the soil, the load is applied at the pile head, and the pile head is free. Slope angles are $20^{\circ}$ and $40^{\circ}$. The undrained shear strength of the soil $c_{u}$ is $70 \mathrm{kPa}$, elastic modulus of the soil at $50 \%$ ultimate stress $E_{50}$ is $14 \mathrm{MPa}$, Poisson's ratio of soil $v_{s}$ is 0.49 , and bulk unit weight $\gamma_{s}$ is $18 \mathrm{kN} / \mathrm{m}^{3}$. C3D8R grids are used for piles and soil. In addition, there is more detailed meshing around the pile. The number of meshes in all models is approximately 25,000 . The bottom boundary of the model is fixed in all directions, and the other boundaries, except for the top boundary, are only fixed in the normal direction. The soil is established based on the Mohr-Coulomb model. The contact surface between pile and soil adopts normal behavior and tangential behavior. Normal behavior is set as a "hard" contact mode, and tangential behavior is set as "penalty" function. The "penalty" factor of the pile side is 0.5 , and that between pile tip and pile-tip soil is considered to approach 1 for the slender pile, and assumed to be 0.5 for rigid pile. The friction angle is taken as a smaller value. In this paper, the friction angle is taken as $10^{\circ}$ and the results obtained from the 3D FEA model for different working conditions are fitted to the data from Georgiadis and Georgiadis, as shown in Figure 9. In general, the fitting is well for any working conditions, proving that the model-

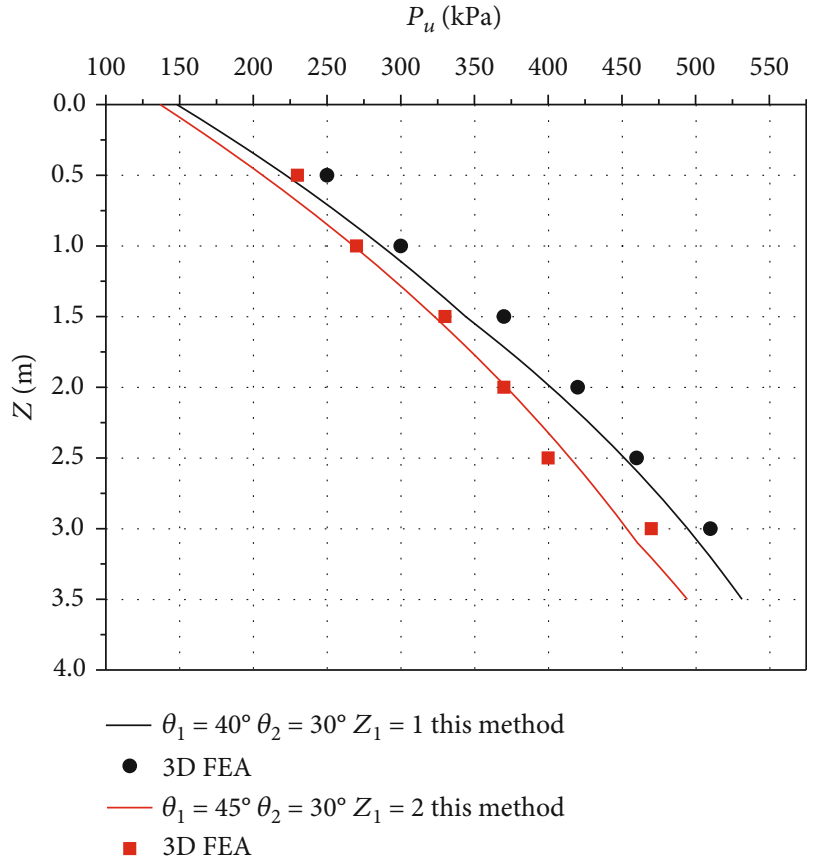

Figure 14: Curve of ultimate soil resistance versus depth.

ing method and the selection of parameters in this paper are reasonable and correct.

3.2. Verification of the Calculation Method. In this section, the proposed method is validated by comparing the loaddisplacement curve of the pile head and the ultimate soil resistance with the 3D FE analysis results of three cases, respectively. The three cases are shown in Table 1. The modeling method and correlation parameters are the same as those in Section 3.1. Figures 10 and 11 show the pile and soil three-dimensional model of case $2\left(\theta_{1}=50^{\circ} ; \theta_{2}=30^{\circ}\right.$; and $Z_{1}=2 \mathrm{~m}$ ). 


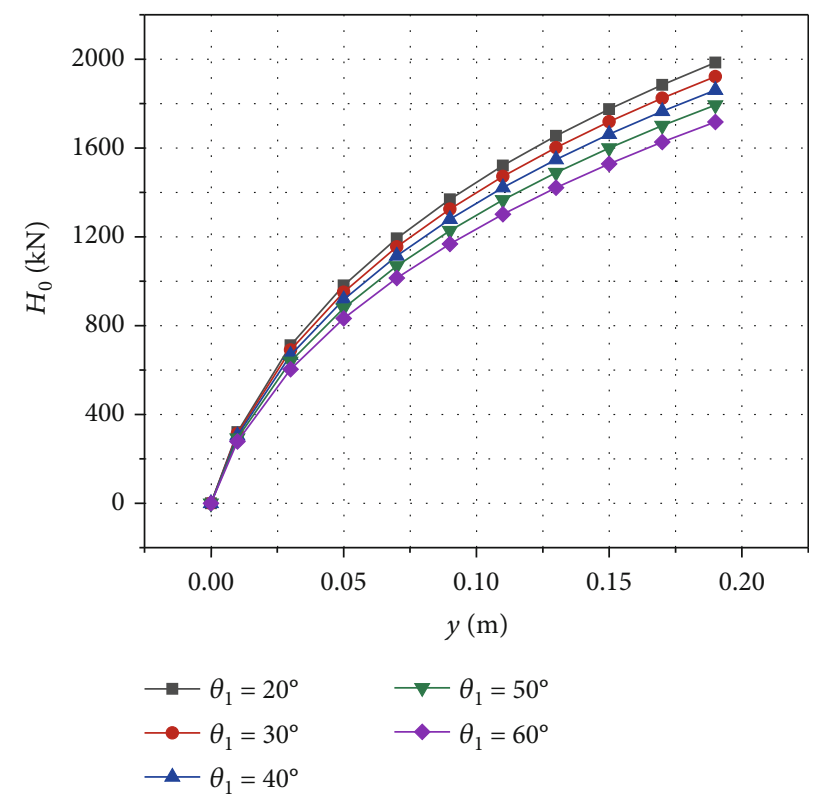

(a)

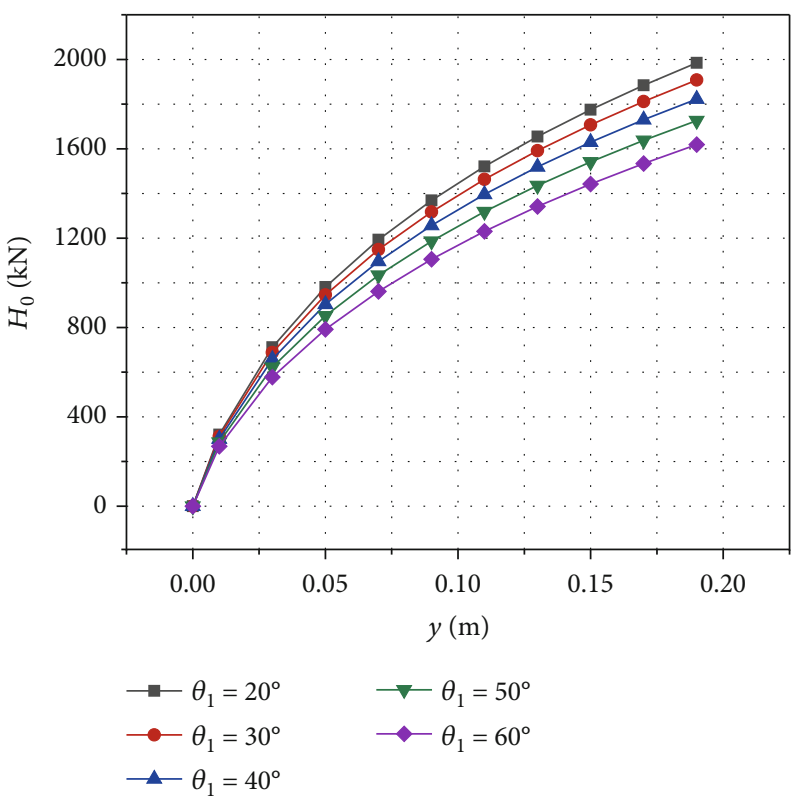

(b)

Figure 15: Load and displacement curve of pile head under the effect of $\theta_{1}$. (a) Considering $Z_{1}=1 \mathrm{~m}$. (b) Considering $Z_{1}=2 \mathrm{~m}$.

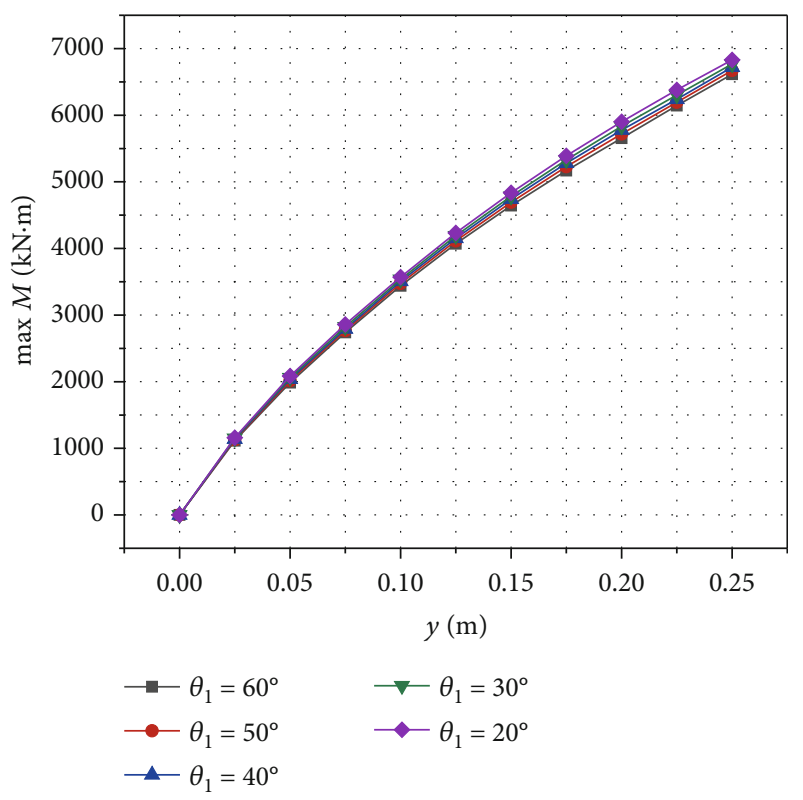

(a)

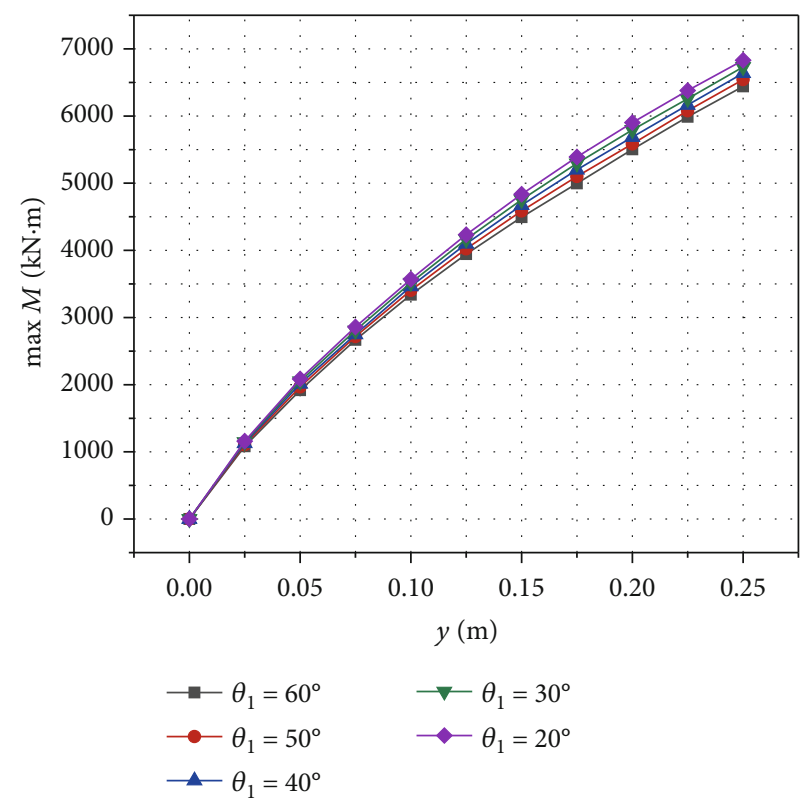

(b)

Figure 16: Effect of $\theta_{1}$ on maximum bending moment. (a) Considering $Z_{1}=1 \mathrm{~m}$. (b) Considering $Z_{1}=2 \mathrm{~m}$.

Case 1 considers two upper slope heights $\left(Z_{1}=1 \mathrm{~m}, 3 \mathrm{~m}\right)$ as variates under the same slope angle $\left(\theta_{1}=40^{\circ} ; \theta_{2}=0^{\circ}\right)$. The pile head displacement of Case 1 is shown in Figure 12. The theoretical calculation has a good agreement with the result of the 3D FE analysis. And Figure 13 shows the loaddisplacement curve of the pile head of Case 2. In Case 2, two upper slope angles $\left(\theta_{1}=50^{\circ}, \theta_{1}=40^{\circ}\right)$, one lower slope angle $\left(\theta_{2}=30^{\circ}\right)$, and one upper slope height $\left(Z_{1}=2 \mathrm{~m}\right)$ are considered. The verification result is good.
Case 3 carries out a verification between the theoretical ultimate soil resistance and the results of 3D FE analysis under different angles and heights. A higher degree polynomial is used to accurately fit the shearing force curve of the pile which is obtained from the three-dimensional model $[26,31]$. The curve of soil resistance $p$ versus pile depth $Z$ under different lateral load $H_{0}$ is obtained by differentiating the fitted shearing force curve of the pile. Through combining $p-Z$ curves and the pile displacement curves under 


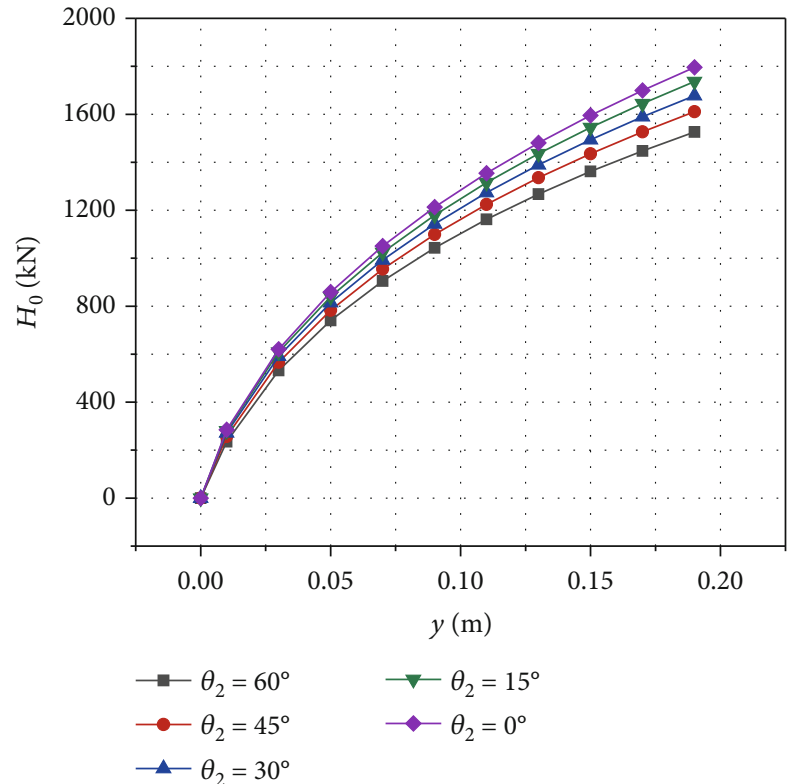

(a)

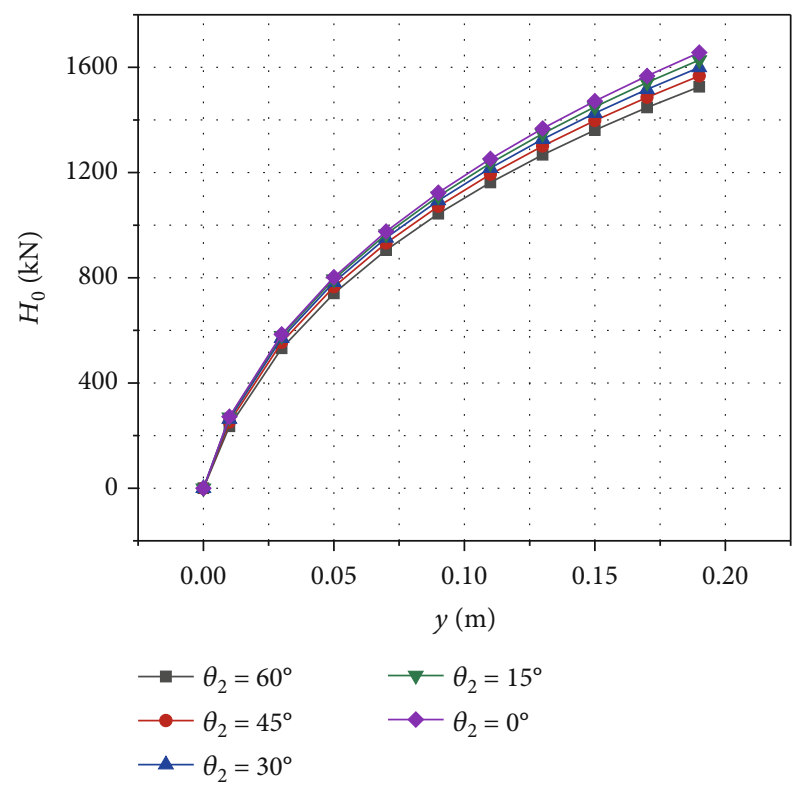

(b)

Figure 17: Effect of $\theta_{2}$ on the load-displacement curve of pile head. (a) Considering $Z_{1}=1 \mathrm{~m}$. (b) Considering $Z_{1}=2 \mathrm{~m}$.

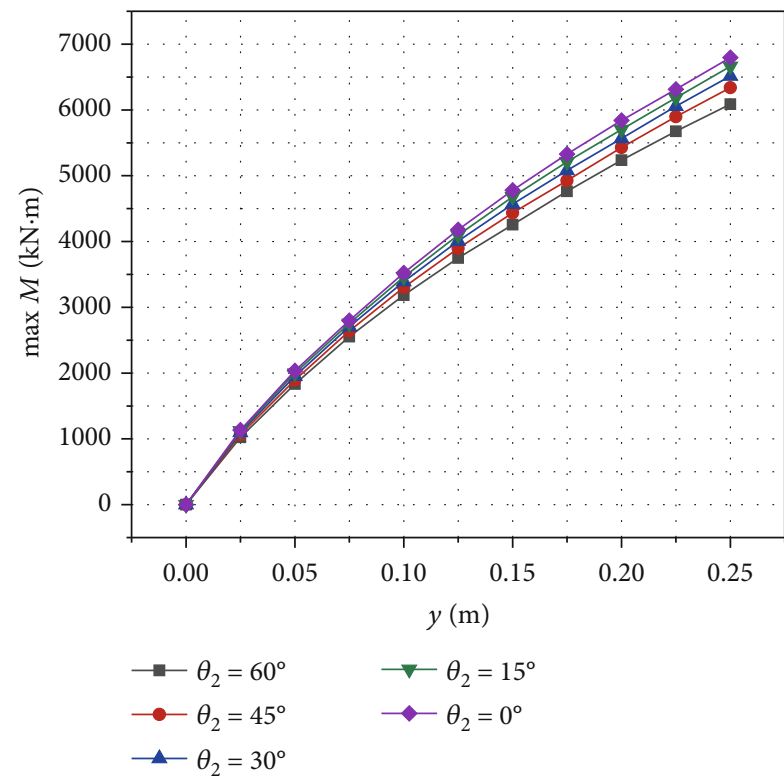

(a)

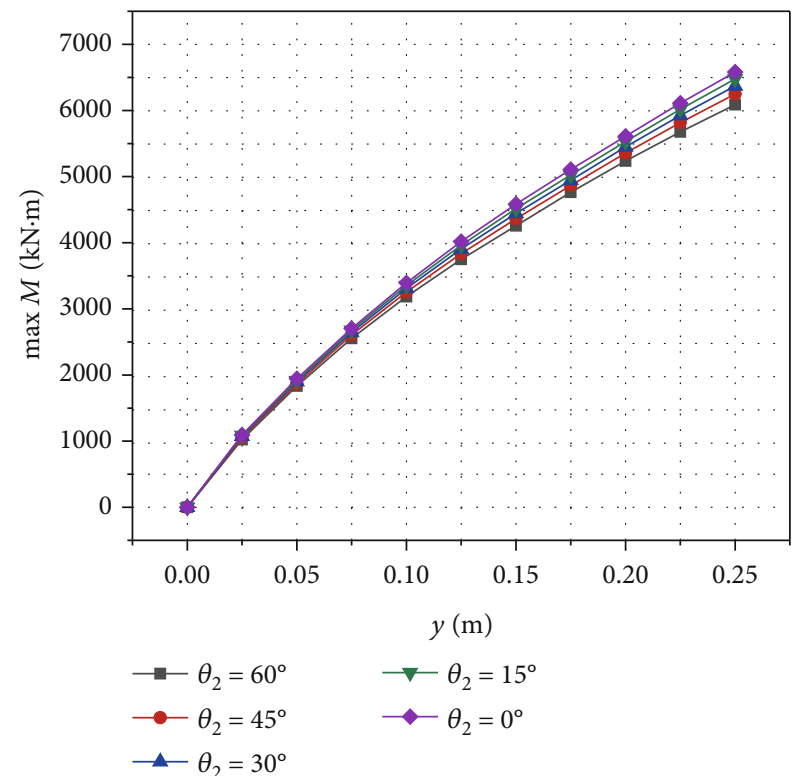

(b)

Figure 18: Effect of $\theta_{2}$ on maximum bending moment. (a) Considering $Z_{1}=1 \mathrm{~m}$. (b) Considering $Z_{1}=2 \mathrm{~m}$.

different lateral loads $H_{0}$, the ultimate soil resistance of each point of the pile is obtained. The verification result is displayed in Figure 14. The theoretical result is in good agreement with the data of 3D FE analysis.

\section{Parameter Analysis}

4.1. The Effect of Upper Slope Angle $\theta_{1}$. In this section, the effect of $\theta_{1}$ on the pile under lateral load is discussed for the case of $\theta_{2}=20^{\circ}$, and the height of upper slope $Z_{1}=1 \mathrm{~m}$ and
$2 \mathrm{~m}$ by selecting 5 values of $\theta_{1}=60^{\circ}, 50^{\circ}, 40^{\circ}, 30^{\circ}, 20^{\circ}$ as variables. And calculation parameters are pile length $L=15 \mathrm{~m}$, diameter $D=1 \mathrm{~m}$, elastic modulus of pile $E_{p}=2.9 \times 10^{7} \mathrm{kPa}$, the undrained shear strength of the soil $c_{u}=70 \mathrm{kPa}$, and the elastic modulus $E_{50}=14 \mathrm{MPa}$.

Figures 15(a) and 15(b) show the influence of different $\theta_{1}$ on the load-displacement curve for the case of $Z_{1}=1 \mathrm{~m}$ and $2 \mathrm{~m}$, respectively. Under the same lateral load, the deflection of the pile head increases with the increment of $\theta_{1}$. And the deflection growth rate of the pile head is greater when the 
lateral load becomes larger. In addition, with the augmentation of $Z_{1}$, the influence of the upper slope is enhanced, and the dispersion of load-displacement curves under different slope conditions becomes larger. For example, considering that $\theta_{1}$ goes up from $0^{\circ}$ to $60^{\circ}$, the pile head deflection increases by $34.3 \%$ under the condition that the lateral load is $1500 \mathrm{kN}$ and $Z_{1}=1 \mathrm{~m}$. And the maximum growth rate can reach $51 \%$ for the case of $Z_{1}=2 \mathrm{~m}$.

Figure 16 investigates the curve of maximum bending moment varying with the pile head displacement under the effect of $\theta_{1}$. Compared with the load-displacement curve, $\theta_{1}$ has a similar but smaller influence on the maximum bending moment of the pile. The maximum bending moment of the pile becomes larger when the angle $\theta_{1}$ decreases under the same displacement of the pile head. And the dispersion of curves is pronounced for larger $Z_{1}$. At a pile head displacement $y=0.2 \mathrm{~m}$, the maximum bending moment of the pile for $\theta_{1}=20^{\circ}$ is higher than that for $\theta_{1}=60^{\circ}$ by $4.4 \%$ and $7.2 \%$ for the $Z_{1}=1 \mathrm{~m}$ and $Z_{1}=2 \mathrm{~m}$, respectively.

4.2. The Effect of Lower Slope Angle $\theta_{2}$. In order to investigate the influence of $\theta_{2}$ on the laterally loaded pile, $\theta_{2}=0^{\circ}, 15^{\circ}$, $30^{\circ}, 45^{\circ}$, and $60^{\circ}$ are selected as variables in this section. When $Z_{1}=1 \mathrm{~m}, 2 \mathrm{~m}$, and $\theta_{1}$ is $60^{\circ}$, the variation rules of pile head deflection and maximum bending moment are analyzed. The calculation parameters of pile and soil are the same as those in Section 4.1 .

Figures 17(a) and 17(b) show the influence of different $\theta_{2}$ on the load-displacement curve under the different upper slope heights $Z_{1}$, respectively. The figures represent that as the angle $\theta_{2}$ increases, the displacement of the pile head under the same load raises nonlinearly. And the growth rate of deflection is positively correlated with $\theta_{2}$. Besides, the influence of the lower slope can be weakened, and the dispersion of load-displacement curves under different slope conditions becomes smaller when the upper slope height $Z_{1}$ increases. Considering that $\theta_{2}$ goes up from $0^{\circ}$ to $60^{\circ}$, the pile head deflection increases by $40 \%$ under the condition that the lateral load is $1500 \mathrm{kN}$ and $Z_{1}=1 \mathrm{~m}$. When $Z_{1}$ is $2 \mathrm{~m}$, the maximum growth rate is $20 \%$.

Figure 18 shows the effect of $\theta_{2}$ in the maximum bending moment. The maximum bending moment of the pile becomes larger when the angle $\theta_{2}$ decreases under the same displacement of the pile head. And the dispersion of curves is smaller for larger $Z_{1}$. At a pile head displacement $y=0.2$ $\mathrm{m}$, the maximum bending moment of the pile for $\theta_{1}=0^{\circ}$ is higher than that for $\theta_{2}=60^{\circ}$ by $11.6 \%$ and $7.1 \%$ for the $Z_{1}$ $=1 \mathrm{~m}$ and $Z_{1}=2 \mathrm{~m}$, respectively.

4.3. The Effect of the Normalized Height $Z_{1} / D$. To study the influence of the normalized height $Z_{1} / D$, this section considers $Z_{1} / D$ as $0,0.5,1.0,2.0,4.0$, and 5.0. And upper slope angle $\theta_{1}=60^{\circ}$, lower slope angle $\theta_{2}=30^{\circ}$. Other calculation parameters of pile and soil are the same as in Section 4.1.

Figure 19 shows the load-displacement curves of the pile head considering different sloping conditions. It indicates that the augmentation in $Z_{1} / D$ increases the deflection of the pile head. When the normalized height $Z_{1} / D$ changes from 0 to 2 , the pile head deflection increases

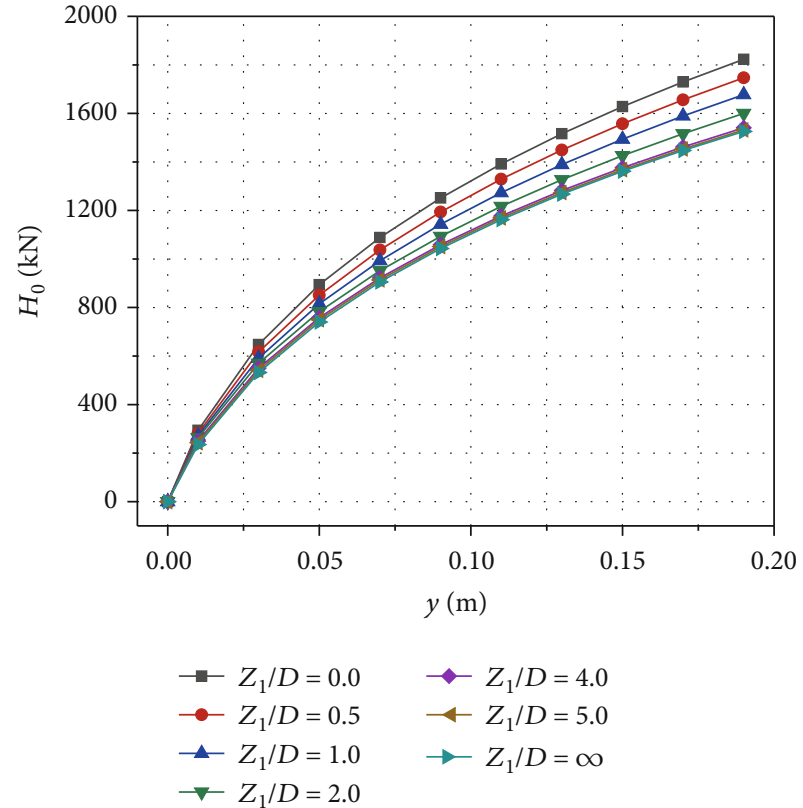

FIgUre 19: Effect of $Z_{1} / D$ on the deflection of the pile head.

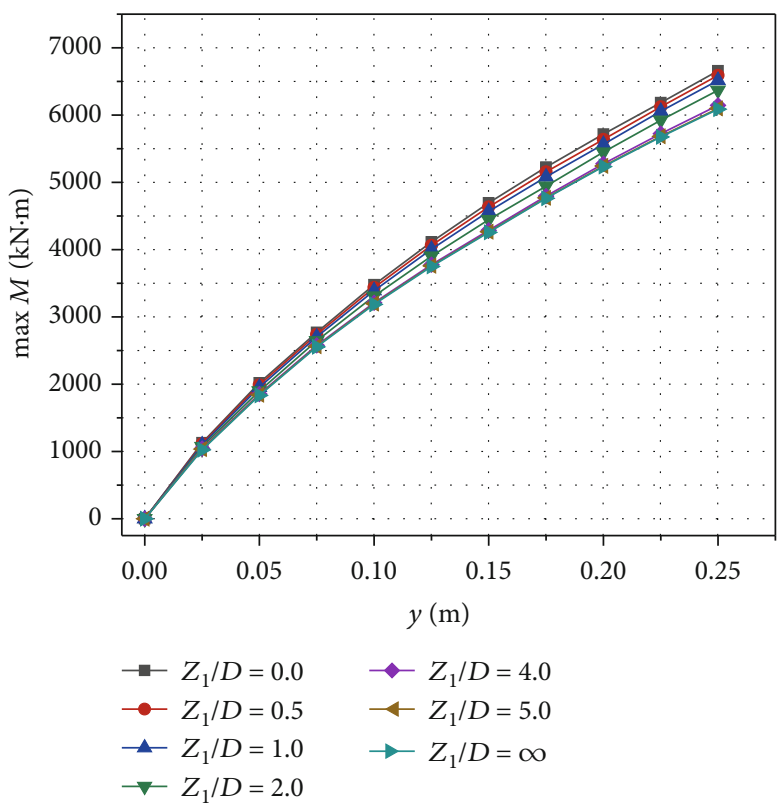

Figure 20: Effect of $Z_{1} / D$ on maximum bending moment.

rapidly. For the lateral load $H_{0}=1500 \mathrm{kN}$, the growth rate of pile head deflection is $32 \%$. When the normalized height is greater than 2, the growth rate of deflection gradually becomes flat. For $Z_{1} / D=5$ and applied load $H_{0}=$ $1500 \mathrm{kN}$, the deflection of the pile head is only $10 \%$ higher than that for $Z_{1} / D=2 \mathrm{~m}$. It also can be seen that the deflection of the pile head is similar to that for the case of $Z_{1} / D=\infty$ when the normalized height $Z_{1} / D$ exceeds 5 in Figure 19.

The influence of the normalized height $Z_{1} / D$ on the maximum bending moment of the pile is illustrated in Figure 20. 
The maximum bending moment is smaller for larger $Z_{1} / D$ under the same deflection of the pile head. The $\max M$ of a pile decreases steeply first and then gently with the increase of the normalized height $Z_{1} / D$. When the value of $Z_{1} / D$ exceeds 5 , the normalized height has no effect on the maximum bending moment. However, the effect of the increase in $Z_{1} / D$ on $\max M$ is quite small. When the displacement of the pile head $y=0.2 \mathrm{~m}$, the growth rate of maximum bending moment of the pile is only $9.2 \%$ with the normalized height $Z_{1} / D$ range 0 to $\infty$.

\section{Conclusion}

This paper has proposed the $p-y$ curve which is suitable for a concave slope, and the lateral response of a pile has been studied. Equations of initial stiffness $K_{i}$ varying with depth were obtained through the reduction coefficient method and the normalization method. The nonlinear formulas of the ultimate soil resistance with depth were obtained by using the soil damaged model in front of piles. The rationality of the theory in this paper was verified by comparing the result of three-dimensional finite element analysis. The upper slope angle $\theta_{1}$, the lower slope angle $\theta_{2}$, and the normalized height $Z_{1} / D$ were discussed. The following conclusions can be drawn:

(1) Both ultimate soil resistance and deflection of pile head were predicted using a new method in this paper, which is in good agreement with those calculated by $3 \mathrm{D} \mathrm{FE}$ analysis

(2) The slope angle $\left(\theta_{1}, \theta_{2}\right)$ has a significant effect on the pile head deflection and a moderate effect on the maximum bending moment. Both deflection and maximum bending moment increase with the increase in slope angle. In addition, the effects of the angle and the height of the upper slope are mutual. As $Z_{1}$ increases, the influence of the lower slope angle $\theta_{2}$ weakens and that of the upper slope angle $\theta_{1}$ enhances

(3) The normalized height $Z_{1} / D$ is also a remarkable factor for the concave slope. The increase of the deflection and maximum bending moment is greater for larger $Z_{1} / D$ under the same load. And the influence scope of $Z_{1} / D$ is 0 to 5

(4) The response of lateral load piles on concave slopes differs markedly from the response of lateral load piles on single-angle slopes. There is a large error using the existing $p-y$ curves to predict the response of the laterally loaded pile on the concave slope. Thus, the proposed $p-y$ curve of a concave slope in this paper has practical value

\section{Data Availability}

The data used to support the findings of this study are available from the corresponding author upon request.

\section{Conflicts of Interest}

The authors declare that there are no conflicts of interest regarding the publication of this paper.

\section{Acknowledgments}

This work is supported by National Natural Science Foundation of China (Grant Nos. 51678570 and 51978665).

\section{References}

[1] H. G. Poulos and E. H. Davis, Pile Foundation Analysis and Design, John Wiley \& Sons, New York, NY, 1980.

[2] L. Zhang, Drilled Shafts in Rock-Analysis and Design, Balkema, London (UK), 2005.

[3] P. Liu, C. Jiang, M. Lin, L. Chen, and J. He, "Nonlinear analysis of laterally loaded rigid piles at the crest of clay slopes," Computers and Geotechnics, vol. 126, p. 103715, 2020.

[4] P. Liu, L. Chen, C. Huawei, and C. Jiang, "A method for predicting lateral deflection of large-diameter monopile near clay slope based on soil-pile interaction," Computers and Geotechnics, vol. 135, article 104180, 2021.

[5] L. J. Chen, C. Jiang, L. Pang, and P. Liu, "Lateral soil resistance of rigid pile in cohesionless soil on slope," Computers and Geotechnics, vol. 135, p. 104163, 2021.

[6] Y. Wang, Y. F. Yi, C. H. Li, and J. Q. Han, “Anisotropic fracture and energy characteristics of a Tibet marble exposed to multi-level constant-amplitude (MLCA) cyclic loads: a labscale testing," Engineering Fracture Mechanics, vol. 244, no. 10, p. 107550, 2021.

[7] L. C. Reese and W. F. Van Impe, Single Piles and Pile Group under Lateral Loading, A. A. Balkema, Ed., CRC press, Rotterdam, 2001.

[8] H. Matlock, "Correlations for design of laterally loaded piles in soft clay," Proceedings 2nd Offshore Technology Conf., 1970, pp. 577-594, OTC, Houston, 1970.

[9] API (American petroleum institute), Recommended Practice for Planning, Designing and Constructing Fixed Offshore Platforms. API RP-2A, API, Washington DC, 15th edition, 1984.

[10] L. U. Cheng, X. C. Xu, and S. X. Chen, "Model test and numerical simulation of horizontal bearing capacity and impact factors for foundation piles in slope," Rock and Soil Mechanics, vol. 9, no. 26, pp. 85-91, 2014.

[11] Y. I. Ping-bao, Z. H. Ming-hua, Z. H. Heng, and H. E. Wei, "Stability analysis of pile column bridge pile considering slope effect," Journal of Hunan University, vol. 43, no. 11, pp. 20-25, 2016.

[12] Y. S. Deng, M. H. Zhao, and X. J. Zhou, "Research progress of bearing characteristics of pile column at steep slope in mountain areas," Journal of Highway and Transportation Research and Development, vol. 29, no. 6, pp. 37-45, 2012.

[13] L. C. Reese, W. R. Cox, and F. D. Koop, "Field testing and analysis of laterally loaded piles in stiff clay," in Proceedings 7 th Offshore Technology Conference, OTC, pp. 671-690, Houston, 1975.

[14] K. Georgiadis and M. Georgiadis, "Undrained lateral pile response in sloping ground," Journal of Geotechnical and Geoenviromental Engineering, vol. 136, no. 11, pp. 14891500, 2010. 
[15] K. Georgiadis and M. Georgiadis, "Development of $p-y$ curves for undrained response of piles near slopes," Computers and Geotechnics, vol. 40, pp. 53-61, 2012.

[16] C. Y. Wu, J. P. Qiao, and L. B. Lan, "Research on slope shape of landslide based on GIS technique," Journal of Natural Disasters, vol. 2005, no. 3, pp. 34-37, 2005.

[17] H. M. Fan, T. L. Wang, and L. L. Zhou, "Study on temporal and spatial variation of current velocity on different form slopes," Journal of soil and Water Conservation, vol. 21, no. 6, pp. 35-38, 2007.

[18] M. Georgiadis, C. Anagnostopoulos, and S. Saflekou, "Interaction of laterally loaded piles," in Proceedings, Fondations Profondes, Ponts et Chaussees, pp. 177-184, Paris, 1991.

[19] S. S. Rajashree and T. G. Sitharam, "Nonlinear finite-element modeling of batter piles under lateral load," Journal of Geotechnical and Geoenviromental Engineering, vol. 127, no. 7, pp. 604-612, 2001.

[20] B. T. Kim, N. K. Kim, W. J. Lee, and Y. S. Kim, "Experimental load-transfer curves of laterally loaded piles in Nak-Dong river sand," Journal of Geotechnical and Geoenviromental Engineering, vol. 130, no. 4, pp. 416-425, 2004.

[21] R. Liang, K. Yang, and J. Nusairat, " $P-Y$ criteria for rock mass," Journal of Geotechnical and Geoenviromental Engineering, vol. 135, no. 1, pp. 26-36, 2009.

[22] K. Yang, "Analysis of laterally loaded drilled shafts in rock," Department of Civil Engineering, Univ. of Akron, 2006, Ph.D. dissertation.

[23] J. D. Murff and J. M. Hamilton, "P-ultimate for undrained analysis of laterally loaded piles," Journal of Geotechnical Engineering, vol. 119, no. 1, pp. 91-107, 1993.

[24] C. M. Martin and M. F. Randolph, "Upper-bound analysis of lateral pile capacity in cohesive soil," Géotechnique, vol. 56, no. 2, pp. 141-145, 2006.

[25] M. F. Randolph and G. T. Houlsby, "The limiting pressure on a circular pile loaded laterally in cohesive soil," Géotechnique, vol. 34, no. 4, pp. 613-623, 1984.

[26] C. Jiang, J. L. He, L. Liu, and B. W. Sun, "Effect of loading direction and slope on laterally loaded pile in sloping ground," Advances in Civil Engineering, vol. 2018, no. 4, pp. 1-12, 2018.

[27] D. P. Carter, A Non-Linear Soil Model for Predicting Lateral Pile Response, Dept. of Civil Engineering, Univ. of Auckland, 1984, Ph.D. dissertation.

[28] R. L. Kondner, "Hyperbolic stress-strain response: cohesive soils," Journal of Soil Mechanics and Foundation Engineering Division, vol. 89, no. 1, pp. 115-143, 1963.

[29] P. K. Robertson, M. P. Davies, and R. G. Campanella, "Design of laterally loaded driven piles using the flat dilatometer," Geotechnical Testing Journal, vol. 12, no. 1, pp. 30-38, 1989.

[30] M. H. Yang, B. Deng, and M. H. Zhao, "Experimental and theoretical studies of laterally loaded single piles in slopes," Journal of Zhejiang University-SCIENCE A, vol. 20, no. 11, pp. 838-851, 2019.

[31] S. Mezazigh and D. Levacher, "Laterally loaded piles in sand: slope effect on $p-y$ reaction curves," Canadian Geotechnical Journal, vol. 35, no. 3, pp. 433-441, 1998. 